\title{
APLICAÇÃO SUPERFICIAL DE CALCÁRIO NO SISTEMA PLANTIO DIRETO CONSOLIDADO EM SOLO ARENOSO
}

\author{
SURFACE APPLICATION OF LIME ON NO-TILLAGE
}

\author{
Danilo dos Santos Rheinheimer ${ }^{1}$ Edilceu João da Silva Santos ${ }^{2}$ \\ João Kaminski ${ }^{3}$ Flávio Moreira Xavier ${ }^{4}$
}

RESUMO

A aplicação superficial de calcário no sistema plantio direto (SPD) consolidado pode ser uma alternativa para a correção da acidez do solo. Este trabalho avaliou as produtividades das culturas e os atributos químicos do solo afetados pela reaplicação de calcário no SPD. O Experimento foi conduzido na área Experimental do Departamento de Solos na Universidade Federal de Santa Maria (RS), sobre um Argisolo vermelho distrófico avênico, textura arenosa/argilosa sob SPD estabelecido há cinco anos, com pH 5,0 e 13, 140 e $610 \mathrm{~g} \mathrm{~kg}^{-1}$ de $\mathrm{MO}$, argila e areia, respectivamente. Aplicaram-se zero, 1,2, 1,8 e 3,6t hat de calcário, sobre a superfície sem incorporação, e cultivaram-se milho em 1994, aveia preta em 1995 e 96 e soja em 1996 e 97. Avaliou-se o rendimento de grãos de milho e soja e a massa seca de aveia preta. Coletaram-se amostras de solo aos 6, 12 e 18 meses após a aplicação do calcário, em 4 profundidades $(0-2,5$, 2,5-5, 5-10 e 10-15cm) nas quais se determinaram os atributos químicos relacionados à acidez do solo. $O$ delineamento experimental foi o de blocos ao acaso, com 4 repetições. A reaplicação superficial de calcário não afetou o rendimento das culturas, mas diminuiu os teores de alumínio trocável, e aumentou o pH e os teores de cálcio e magnésio até a profundidade de $5 \mathrm{~cm}$.

Palavras-chave: sistema plantio direto, rendimento, acidez do solo, calagem.

\section{SUMMARY}

Surface liming is an alternative way to correct soil acidity. The objective of this study was to evaluate the effects of surface liming on soil properties and crop yield under no-tillage. The experiment was carried out at Federal University of Santa Maria, Southern Brazil, on a Typic Hapludult, under no-tillage, for five years, with $\mathrm{pH} 5.0,13,140$ and $610 \mathrm{~g} \mathrm{~kg}^{-1} \mathrm{OM}$, clay and sand, respectively. The lime rates used were 0, 1.2, 1.8 and
3.6Mg ha ${ }^{-1}$, applied on the soil surface without incorporation. The crops used were corn (94/95), black oat (95 and 96) and soybean (95/96 and 96/97). Grain yield was evaluated for corn and soybeans; dry matter production was evaluated for black oats. Six, 12, and 18 moths after liming, soil was sampled at four depths, $0-2.5,2.5-5,5-10$ and $10-15 \mathrm{~cm}$ to measure some attributes related to soil acidity. Treatments were set up in a complete block design with four replications. Superficial applied lime did not induce crop yield differences, but modified acidity and increased $\mathrm{pH}$, calcium and magnesium contents in the $0-5 \mathrm{~cm}$ layer.

Key words: no-tillage, yield crop, soil acidity, liming.

\section{INTRODUÇÃO}

A área agrícola cultivada no sistema plantio direto (SPD) tem crescido no Rio Grande do Sul. É um método eficiente de conservação do solo, mas as informações sobre o manejo das culturas e da fertilidade do solo ainda são escassas.

O cultivo contínuo do solo, geralmente, propicia a sua acidificação, independente do sistema de preparo. No SPD, há a tendência da diminuição do $\mathrm{pH}$ do solo e aumento nos teores de alumínio trocável na camada superficial (BLEVINS et al., 1977 e 1978; CASSOL \& ANGHINONI, 1995), surgindo a necessidade de reaplicação de calcário. A acidificação do solo nesse sistema é causada, principalmente, pela decomposição dos resíduos culturais que são deixados na superfície do solo e/ou desbalanço no ciclo do nitrogênio. A aplicação superficial

\footnotetext{
${ }^{1}$ Engenheiro Agrônomo, MSc., Professor Assistente, Departamento de Solos, Centro de Ciências Rurais (CCR), Universidade Federal de Santa Maria (UFSM), 97105-900, Santa Maria, RS. Danilo@creta.ccr.ufsm.br. Autor para correspondência.

${ }^{2}$ Engenheiro Agrônomo, MSc., Professor Substituto, Departamento de Solos, CCR, UFSM.

${ }^{3}$ Engenheiro Agrônomo, Doutor, Professor Titular aposentado, Departamento de Solos, CCR, UFSM.

${ }^{4}$ Engenheiro Agrônomo, Especialista, Professor Titular aposentado, Departamento de Solos, CCR, UFSM.

Recebido para publicação em 16.05.98. Aprovado em 16.06.99
} 
dos adubos nitrogenados amoniacais liberam íons hidrogênio durante a nitrificação que, associados à lixiviação do nitrato, provocam o abaixamento do pH (MOSCHLER et al., 1973; BLEVINS et al., 1977, 1978 e 1983). Esse abaixamento do $\mathrm{pH}$ pode se tornar limitante à produção vegetal, em função da toxidez de alumínio e/ou de manganês e do desbalanço na disponibilidade de nutrientes às plantas.

Como há possibilidade de movimentação do calcário aplicado na superfície do solo no SPD para as camadas mais profundas, a calagem superficial pode ser uma alternativa sem modificar as condições do sistema (MIELNICZUK et al., 1995). Isso devido à formação de uma rede de canais contínuos e profundos (até $40-50 \mathrm{~cm}$ ), oriundos da morte das raízes e da atividade de minhocas e corós (LAL \& VANDOREN, 1990). Também, a liberação de compostos orgânicos hidrossolúveis e a lixiviação de nitratos podem favorecer a descida de cálcio e magnésio no perfil do solo. PEARSON et al. (1962), BLEVINS et al. (1977) e CAIRES et al. (1998) verificaram que a aplicação superficial de calcário, seguida de fertilizantes nitrogenados, proporcionou a formação de sais solúveis de nitrato, os quais foram percolados pelo movimento descendente da água.

O objetivo do presente trabalho foi o de avaliar o efeito da reaplicação de calcário no sistema plantio direto consolidado na produtividade das culturas e nos atributos químicos relacionados à acidez do solo.

\section{MATERIAL E MÉTODOS}

O experimento foi conduzido na área experimental do Departamento de Solos da Universidade Federal de Santa Maria (RS), num Argissolo vermelho, distrófico avênico, textura arenosa/argilosa, relevo ondulado, substrato arenito. A área foi cultivada com milho (Zea mays L.) e soja (Glycine max Merril) em cultivo convencional até 1988. Esse, implantado sobre campo nativo, caracterizava-se pelo uso de aração e gradagem antecedendo os cultivos de verão e de uma gradagem para a implantação das culturas de cobertura do solo de inverno. A semeadura era feita em nível, com a presença de terraços de base larga. As espessuras dos horizontes A e E são de 90 e $30 \mathrm{~cm}$, respectivamente (ALBUQUERQUE $\boldsymbol{e t}$ al., 1996). A análise do solo da camada $0-20 \mathrm{~cm}$ tinha $140,250,400$ e $210 \mathrm{~g} \mathrm{~kg}^{-1}$ de argila, silte, areia fina e areia grossa, respectivamente; $11 \mathrm{~g} \mathrm{~kg}^{-1}$ de matéria orgânica; $\mathrm{pH}$ em água 4,$8 ; 2,90 \mathrm{~mol} \mathrm{~kg}^{-1}$ e $1,70 \mathrm{cmol} \mathrm{kg}^{-1}$ de $\mathrm{Al}$ trocáveis, $3,2 \mathrm{mg} \mathrm{kg}^{-1}$ de $\mathrm{P}$ e $35 \mathrm{mg} \mathrm{kg}^{-1}$ de $\mathrm{K}$ disponível. Em novembro de 1988, foi feita calagem para elevar o pH do solo a $6,0\left(3,1 \mathrm{t} \mathrm{ha}^{-1}\right)$, utilizando-se calcário dolomítico com $60 \%$ de PRNT. A partir daquele momento, adotou-se o sistema plantio direto, sendo cultivado milho/aveia + ervilhaca até a safra 1993/94. Em setembro de 1994, coletaram-se amostras de solo, cujos resultados químicos foram: $\mathrm{pH}$ em água $=5,0 ;$ índice $\mathrm{SMP}=5,8 ; \mathrm{Al}=0,40 \mathrm{e}$ $\mathrm{Ca}+\mathrm{Mg}=3,00 \mathrm{cmol} \mathrm{dm}^{-3} ; \mathrm{P}=10$ e $\mathrm{K}=75 \mathrm{mg} \mathrm{dm}^{-3}$, servindo como base para os tratamentos com calagem.

Em 03 de outubro de 1994, instalou-se o experimento, cujos tratamentos usados foram baseados na estimativa da correção da acidez para pH 6,0. Os tratamentos consistiram na aplicação de calcário superficial nas doses de 0, 1,2 (1/3 SMP), 1,8 (1/2 SMP) e 3,6t ha-1 (1 SMP). Aos 12 meses após a implantação, reaplicou-se a dose no tratamento $1 / 3$ SMP e aos 24 meses, no 1/2 SMP. O delineamento experimental utilizado foi o de blocos ao acaso, com 4 repetições. As parcelas mediam 10 x 15m, distribuídas ao longo do declive (7\%), entre os terraços. Cultivaram-se milho, aveia preta, soja, aveia preta e soja nas safras 94/95, 95, 95/96, 96 e 96/97, respectivamente. Foram adicionados N, P e K nos cultivos de verão, baseados em análises do solo e nas doses estabelecidas pela Comissão de Fertilidade do Solo do Núcleo Regional Sul de Ciência do Solo (COMISSÃO DE FERTILIDADE DO SOLO, 1995). Determinaram-se o rendimento de grãos do milho e soja e a massa seca da parte aérea da aveia preta em pleno florescimento.

Coletaram-se amostras de solo (20 subamostras/parcela) aos 6, 12 e 18 meses após a aplicação do calcário, nas profundidades de 0-2,5, 2,5-5, $5-10$ e $10-15 \mathrm{~cm}$. O solo foi seco ao ar e passado em peneira de $2 \mathrm{~mm}$. Avaliaram-se o $\mathrm{pH}$ em $\mathrm{CaCl}_{2}$ e os teores de cálcio, magnésio e alumínio trocáveis (TEDESCO et al., 1995). Calcularam-se a saturação por bases e por alumínio.

As produtividades de grãos do milho e da soja e de massa seca da aveia preta foram submetidas à análise de variância a 5\% de significância. Os valores de $\mathrm{pH}$ em $\mathrm{CaCl}_{2}$ e dos teores de cálcio, magnésio e alumínio trocáveis foram submetidas à Anova e as médias foram comparadas pelo teste de Tukey $(\mathrm{P}<0,05)$.

\section{RESULTADOS E DISCUSSÃO}

\section{Produtividade das culturas}

A aplicação de calcário não afetou o rendimento de nenhuma das culturas estudadas (Tabela 1), indicando que o solo ainda apresentava condições adequadas ao desenvolvimento normal das plantas, mesmo que o índice SMP indicasse a necessidade de reposição do calcário. A ausência de resposta à aplicação superficial de calcário no SPD sobre o rendimento das culturas se deve aos valores 
Tabela 1 - Produtividade de grãos de milho e soja e massa seca da parte aérea da aveia preta devido à reaplicação de calcário em superfície no sistema plantio direto em solo arenoso. Média de quatro repetições. Santa Maria (RS), 1997.

\begin{tabular}{|c|c|c|c|c|c|}
\hline \multirow[t]{2}{*}{ Calcário } & \multirow{2}{*}{$\begin{array}{c}\text { Milho } \\
94 / 95\end{array}$} & \multicolumn{2}{|c|}{ Aveia preta } & \multicolumn{2}{|c|}{ Soja } \\
\hline & & 1995 & 1996 & $95 / 96$ & $96 / 97$ \\
\hline $\mathrm{tha}^{-1}$ & \multicolumn{5}{|c|}{ 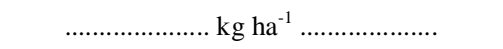 } \\
\hline $0,0^{*}$ & 6.354 & 3.325 & 5.413 & 2.700 & 3.352 \\
\hline 1,2 & 6.224 & 3.263 & 4.547 & 2.708 & 3.607 \\
\hline 1,8 & 5.750 & 3.234 & 5.398 & 2.620 & 3.396 \\
\hline 3,6 & 6.616 & 3.380 & 4.658 & 2.684 & 3.594 \\
\hline $\mathrm{CV}(\%)$ & 11,3 & 17,80 & 14,15 & 8,54 & 8,65 \\
\hline
\end{tabular}

*Não houve efeito significativo do calcário sobre a produção de grãos.

muito baixos de alumínio trocável (saturação por alumínio < $12 \%$ ) e aos médios valores de cálcio e magnésio trocáveis (saturação por bases > $40 \%$ (Tabela 2). Essas condições não causaram impedimentos químicos ao crescimento radicular, e se devem ao efeito residual do calcário aplicado e incorporado ao solo em 1988, antes da implantação do SPD. CAIRES et al. (1998) constataram que a soja não respondeu à aplicação de calcário, num latossolo vermelho-escuro sob SPD com $\mathrm{pH}$ em $\mathrm{CaCl}_{2}$ de 4,5, $32 \%$ de saturação por bases e $18 \%$ de saturação por alumínio, na camada $0-20 \mathrm{~cm}$. No entanto, as altas produtividades obtidas em solos com baixos $\mathrm{pH}$ e presença de alumínio trocável não são exclusividades do SPD, como observado por ERNANI et al. (1998), e sim à interação do alumínio com a matéria orgânica e ao antagonismo com o cálcio e o magnésio.

Mesmo após nove anos da aplicação e incorporação do calcário ao solo, os valores de alumínio, cálcio e magnésio trocáveis não se alteraram substancialmente, demonstrando que o efeito residual do calcário pode se estender por um longo período, até para solos arenosos. AZEVEDO et al. (1996) constataram que o efeito residual do calcário, aplicado na dose recomendada pelo SMP para $\mathrm{pH}$ 6,5, em solo argiloso e com alto teor de matéria orgânica, pode ultrapassar 23 anos, mantendo o $\mathrm{pH}$ e os teores de cálcio e magnésio trocáveis elevados e de alumínio trocável baixo.

As produtividades de milho e soja (Tabela 1) estão muito próximas àquelas máximas obtidas na
Depressão Central do RS, sem suplementação de água. Além da boa disponibilidade de nutrientes, da ausência de elementos tóxicos e do melhor aproveitamento da água no sistema plantio direto, a continuidade desse sistema por vários anos favorece o desenvolvimento e permanência de macroporos e a formação de canais abertos por raízes, minhocas e outros insetos do solo, que são caminhos potencialmente importantes na movimentação descendente da solução do solo e a possibilidade do crescimento das raízes das plantas por esses orifícios (PEARSON $\boldsymbol{e t}$ al., 1962). As paredes desses canais podem representar ambientes ricos em nutrientes e elevar a disponibilidade de nutrientes nos "caminhos" das raízes, sem que isso represente um aumento da fertilidade quando avaliada como um todo no solo.

\section{Alterações nos atributos químicos do solo}

Seis meses após a aplicação superficial de 1,2, 1,8 e 3,6t ha ${ }^{-1}$ de calcário no SPD consolidado, já se observaram elevação do $\mathrm{pH}$ em $\mathrm{CaCl}_{2}(4,5$ para $5,3,5,2$ e 5,4), dos teores de cálcio trocável $(2,4$ para $3,3,3,0$ e $\left.3,7 \mathrm{cmol} \mathrm{dm}^{-3}\right)$ e de magnésio trocável $(1,4$ para $1,7,1,7$ e $\left.1,8 \mathrm{cmol} \mathrm{dm}^{-3}\right)$ e diminuição do alumínio trocável $\left(0,4\right.$ para $0,0,0,0$ e $\left.0,0 \mathrm{cmol} \mathrm{dm}^{-3}\right)$ na camada de $0-2,5 \mathrm{~cm}$, respectivamente. Também, constataram-se efeitos na subsuperfície até a profundidade de $5 \mathrm{~cm}$. A baixa quantidade de acidez desse solo e o pequeno volume de solo em contanto com o calcário limitaram a sua dissolução, e por isso não houve diferenças no $\mathrm{pH}$, nos teores de cálcio e magnésio e nas saturações por bases e alumínio, com as doses. Aos 12 meses após a aplicação do calcário ao solo, os valores de $\mathrm{pH}$, cálcio e magnésio continuaram aumentando, principalmente, na camada superficial. Dos 12 aos 18 meses após a aplicação do calcário, os valores de $\mathrm{pH}$ e os teores de alumínio trocável praticamente estabilizaram-se, enquanto os teores de cálcio e magnésio continuaram aumentando nas camadas de 0-2,5 e 2,5-5cm, proporcionando um leve aumento na saturação por bases (Tabela 2). A reaplicação de $1,2 \mathrm{t}$ ha $^{-1}$ de calcário, no tratamento 1/3 SMP, proporcionou uma continuidade da dissolução do calcário na camada superficial $(0-2,5 \mathrm{~cm})$, cujo valor de $\mathrm{pH}$ e os teores de cálcio e magnésio foram idênticos aos da dose máxima $\left(3,6 \mathrm{tha}^{-1}\right)$.

Ao final de 18 meses após a instalação do experimento, ainda não se observaram diferenças entre as doses de calcário nos atributos relacionados à acidez do solo. Os teores de cálcio foram altos na camada de $0-2,5 \mathrm{~cm}$ e médios nas camadas de 2,5-5, $5-10$ e $10-15 \mathrm{~cm}$ e os de magnésio foram altos em 
Tabela 2 - Saturação com alumínio e com bases aos 6,12 e 18 meses após a aplicação de calcário superficial no sistema plantio direto. Média de quatro repetições. Santa Maria, RS, 1997.

\begin{tabular}{|c|c|c|c|c|c|c|c|c|c|c|}
\hline \multirow{2}{*}{$\begin{array}{l}\text { Calcário } \\
\text { t ha }^{-1}\end{array}$} & \multicolumn{4}{|c|}{ Profundidade, $\mathrm{cm}$} & \multirow[t]{2}{*}{$\mathrm{MP}^{(1)}$} & \multicolumn{4}{|c|}{ Profundidade, $\mathrm{cm}$} & \multirow[t]{2}{*}{ MP } \\
\hline & $0-2,5$ & $2,5-5$ & $5-10$ & $10-15$ & & $0-2,5$ & $2,5-5$ & $5-10$ & $10-15$ & \\
\hline & \multicolumn{5}{|c|}{ Saturação com alumínio, \% } & \multicolumn{5}{|c|}{ Saturação com bases, \% } \\
\hline \multicolumn{11}{|c|}{6 meses após a aplicação do calcário } \\
\hline 0,0 & 9 & 12 & 9 & 9 & 10 & 45 & 41 & 46 & 51 & 47 \\
\hline 1,2 & 0 & 9 & 9 & 8 & 7 & 66 & 52 & 55 & 54 & 56 \\
\hline 1,8 & 0 & 7 & 6 & 8 & 6 & 60 & 52 & 53 & 54 & 55 \\
\hline 3,6 & 0 & 7 & 7 & 8 & 6 & 71 & 54 & 51 & 55 & 56 \\
\hline \multicolumn{11}{|c|}{12 meses após a aplicação do calcário } \\
\hline 0,0 & 9 & 12 & 9 & 9 & 9 & 45 & 43 & 49 & 51 & 48 \\
\hline 1,2 & 0 & 9 & 9 & 7 & 7 & 69 & 53 & 56 & 54 & 57 \\
\hline 1,8 & 0 & 7 & 6 & 6 & 5 & 63 & 55 & 57 & 57 & 58 \\
\hline 3,6 & 0 & 7 & 6 & 6 & 5 & 75 & 58 & 56 & 56 & 59 \\
\hline \multicolumn{11}{|c|}{18 meses após a aplicação do calcário } \\
\hline 0,0 & 10 & 12 & 9 & 9 & 10 & 46 & 40 & 47 & 52 & 47 \\
\hline $1,2+1,2$ & 0 & 4 & 6 & 7 & 5 & 78 & 57 & 56 & 55 & 59 \\
\hline 1,8 & 0 & 4 & 6 & 6 & 5 & 71 & 59 & 55 & 57 & 59 \\
\hline 3,6 & 0 & 3 & 6 & 6 & 5 & 78 & 60 & 53 & 56 & 59 \\
\hline $\mathrm{CV}, \%$ & \multicolumn{5}{|c|}{29,0} & \multicolumn{5}{|c|}{9,5} \\
\hline
\end{tabular}

${ }^{(1)} \mathrm{MP}=$ média ponderada.

todas as camadas analisadas (COMISSÃO DE FERTILIDADE DO SOLO, 1995). Dessa forma, a saturação média por alumínio foi de 3,7 e $6,2 \%$ e a saturação média por bases foi de 75,7 e $56,4 \%$, para as três doses de calcário, na camada $0-2,5 \mathrm{~cm}$ e $2,5-$ $15 \mathrm{~cm}$; enquanto no tratamento sem calcário, a saturação por alumínio e por bases foram de 10 e $47 \%$, respectivamente (Tabela 2 ).

A aplicação superficial de calcário no SPD aumentou o $\mathrm{pH}$ do solo somente até $5 \mathrm{~cm}$ de profundidade, os teores de cálcio e magnésio trocáveis também até os $5 \mathrm{~cm}$, com tendência de maiores valores nas maiores doses, e diminuiu o alumínio trocável apenas na camada de $0-2,5 \mathrm{~cm}$ para as duas primeiras doses e até os $5 \mathrm{~cm}$ para a dose recomendada pelo SMP para $\mathrm{pH} 6,0$ (Figura 1). $\mathrm{O}$ pH em $\mathrm{CaCl}_{2}$ na camada de $0-2,5 \mathrm{~cm}$ passou de 4,3 para 5,4 , 5,7 e 5,7, com as doses $0,1,8,1,2+1,2$ e $3,6 \mathrm{t} \mathrm{ha}^{-1}$, respectivamente, neutralizando por completo o alumínio trocável. Os maiores valores de $\mathrm{pH}$, cálcio e magnésio e os menores de alumínio trocável na camada superficial $(0$ $2,5 \mathrm{~cm})$, com diferença significativa em relação às demais profundidades $(2,5-5,5-10$ e $10-15 \mathrm{~cm})$ são devido à aplicação superficial de calcário (Figura 1).

A movimentação descendente de cálcio e magnésio no perfil do solo no SPD é lenta e influenciada por fatores biológicos e químicos. A manutenção dos resíduos culturais na superfície do solo diminui as variações de temperatura e umidade e favorece a fauna, responsável pela abertura de canais, pelos quais pode ocorrer o transporte de partículas finas de calcário para a subsuperfície (PEARSON et al., 1962; LAL \& VANDOREN, 1990).

No SPD há liberação contínua de substâncias orgânicas hidrossolúveis que, ao se deslocarem ao longo do perfil, podem agir como carregadores de cálcio e magnésio, atuando como ligantes ou pares iônicos, facilitando sua distribuição no perfil. A aplicação superficial de fertilizantes nitrogenados também influencia a movimentação em profundidade de cálcio e magnésio pela produção e lixiviação de nitratos (GROVE \& BLEVINS, 1988). PEARSON et al. (1962), BLEVINS et al. (1977) e CAIRES et al. (1998) verificaram movimentação de cálcio e magnésio após a aplicação superficial de calcário, principalmente, quando na presença da adubação nitrogenada, atribuindo ao nitrato a formação de sais solúveis com cálcio e magnésio.

\section{CONCLUSÕES}

A aplicação superficial de calcário no sistema plantio direto, estabelecido há cinco anos com calagem incorporada no início do sistema, não aumenta os rendimentos de milho e soja.

O calcário adicionado na superfície do solo no SPD aumenta o $\mathrm{pH}$, os teores de cálcio e magnésio, e diminui os de alumínio trocável apenas até a profundidade de $5 \mathrm{~cm}$, após 18 meses da sua aplicação. 


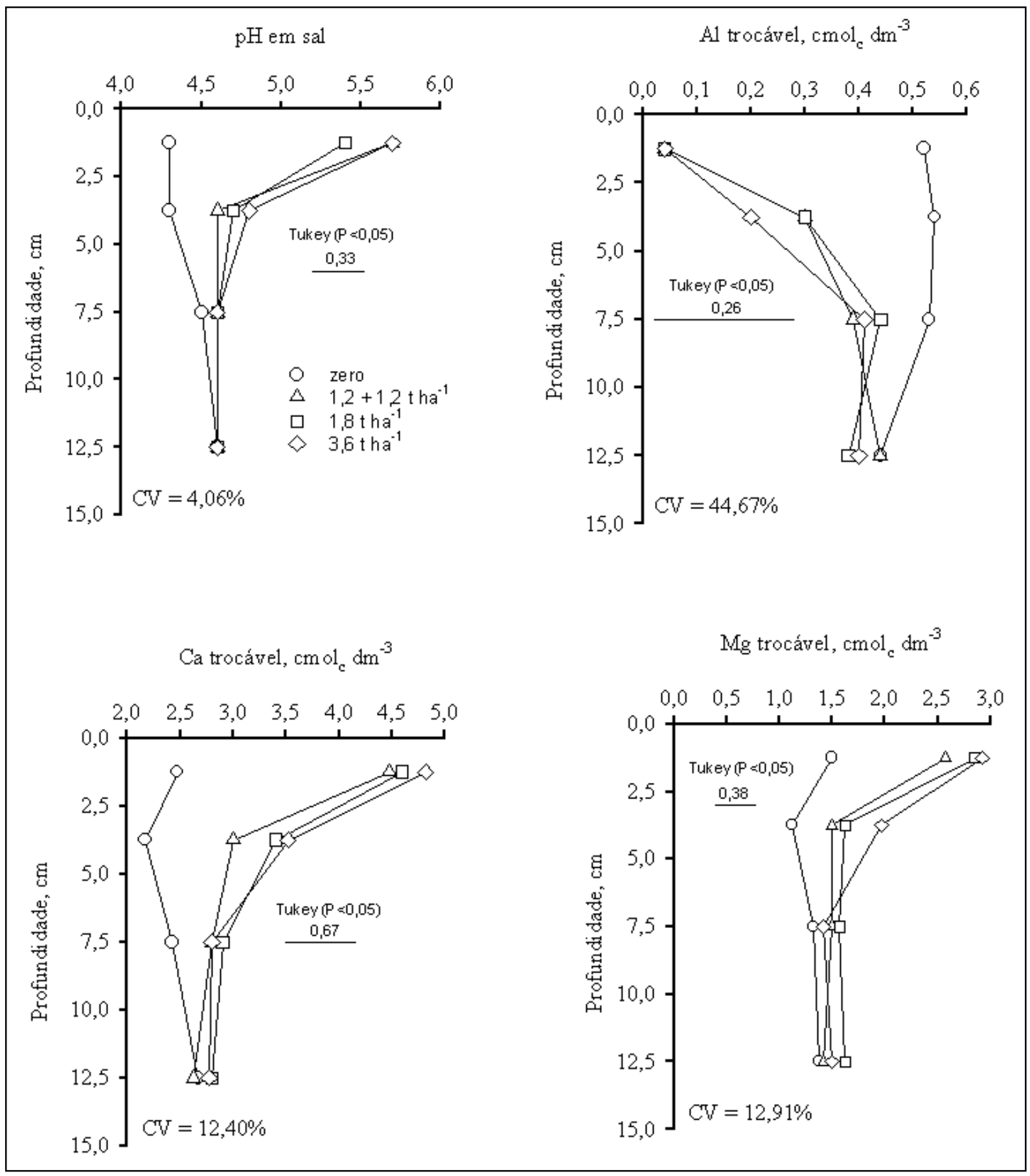

Figura 1 - $\mathrm{pH}$ em $\mathrm{CaCl}_{2}$, alumínio, cálcio e magnésio trocáveis, em diferentes profundidades do solo no sistema plantio direto aos 18 meses após a aplicação superficial de calcário. Média de quatro repetições. Santa Maria, RS, 1997.

\section{REFERÊNCIAS BIBLIOGRÁFICAS}

ALBUQUERQUE, J.A., REINERT, D.J., FIORIN, J.E

Variabilidade de solo e planta em podzólico vermelhoamarelo. Revista Brasileira de Ciência do Solo, Campinas, v.20, n.1., p.151-157, 1996.
AZEVEDO, A.C., KÄMPF, N., BOHNEN, H. Alterações na dinâmica evolutiva de latossolo bruno pela calagem. Revista Brasileira de Ciência do Solo, Campinas, v.20, n.2., p.191$198,1996$.

BLEVINS, R.L., THOMAS, G.W., CORNELUIS, P.L. Influence of no-tillage and nitrogen fertilization on certain soil

Ciência Rural, v. 30, n. 2, 2000. 
properties after 5 years of continuous corn. Agronomy Journal, Madison, v.69, n.2, p.383-386, 1977.

BLEVINS, R.L., MURDOCK, L.W., THOMAS, G.W. Effect of lime applications on no-tillage and conventionally tilled corn. Agronomy Journal, Madison, v.70, n.2, p.322-326, 1978.

BLEVINS, R.L., THOMAS, G.W., SMITH, M.S., et al. Changes in soil properties after 10 years continuous non-tilled and conventionally tilled corn. Soil Tillage Research, Amsterdam, v.3, n.2, p.135-146, 1983.

CAIRES, F.E., CHVEIRI, A.W., MADRUGA, E.F., $\boldsymbol{e} \boldsymbol{t} \boldsymbol{a l}$ Alterações de características químicas do solo e resposta da soja ao calcário e gesso aplicados na superfície em sistema de cultivo sem preparo do solo. Revista Brasileira de Ciência do Solo, Viçosa, v.22, n.1, p.27-34, 1998.

CASSOL, L.C., ANGHINONI, I. Alterações nas características de um solo podzólico vermelho-escuro após quatro anos de cultivo nos sistemas de plantio direto e convencional. CONGRESSO BRASILEIRO DE CIÊNCIA DO SOLO, VIÇOSA, 25, 1995. Resumos... Viçosa : SBCS, 1995. 2429p. p.1843-1844.

COMISSÃO DE FERTILIDADE DO SOLO - RS/SC. Recomendação de adubação e calagem para os estados do Rio Grande do Sul e Santa Catarina. 3 ed. Passo Fundo : SBCS - Núcleo Regional Sul/EMBRAPA/CNPT, 1995. 224p.

ERNANI, P.R., NASCIMENTO, J.A.L., OLIVEIRA, L.C. Increase of grain and green matter of corn by liming. Revista
Brasileira de Ciência do Solo, Viçosa, v.22, n.2, p.275-280, 1998.

GROVE, J.H., BLEVINS, R.L. Correcting soil acidification in continuous corn: $\mathrm{N}$ rate, tillage e time. Communication in Soil Science and Plant Analysis, Madison, v.19, n.7-12, p.1331-1342, 1988.

LAL, R., VANDOREN Jr., D.M. Influence of 25 years of continuous corn production by three tillage methods on water infiltration for two soils in Ohio. Soil Tillage Research, Amsterdam, v.16, n.1, p.71-84, 1990.

MIELNICZUK, J., BURLE, M., FERNANDES, S.V. et al. Eficiência da aplicação de calcário em sistemas de culturas e preparo do solo. CONGRESSO BRASILEIRO DE CIÊNCIA DO SOLO, 25, 1995, Viçosa. Resumos... Viçosa : SBCS, 1995, 2429p. p.1848-1850.

MOSCHLER, W.W., MARTENS, D.C., RICH, C.I., et al. Comparative lime effects on continuous no-tillage and conventionally tilled corn. Agronomy Journal, Madison, v.60, n.5, p.781-783, 1973.

PEARSON, R.W., ABRUNA, F., VICE-CHANCES, J. Effect of lime and nitrogen applications on downward movements of calcium and magnesium in two humid soils of Puerto Rico. Soil Science, Madison, v.93, n.1, p.77-82, 1962.

TEDESCO, M.J., GiAnello, C., BISSANI, C. et al. Análise de solo, plantas e outros materiais. 2 ed. Porto Alegre : Departamento de Solos da UFRGS, 1995. 174p. (Boletim Técnico, 5).

Ciência Rural, v. 30, n. 2, 2000. 